\title{
Borjeson-Forssman-Lehmann Syndrome
}

National Cancer Institute

\section{Source}

National Cancer Institute. Borjeson-Forssman-Lehmann Syndrome. NCI Thesaurus.

Code 1157122.

An X-linked recessive condition caused by mutation(s) in the PHF6 gene, encoding PHD finger protein 6 . It is characterized by severe intellectual disability, epilepsy,

hypogonadism, hypometabolism, and obesity. 